\title{
A Propósito do Carbonato de Sódio
}

$O$ estudante de Química afirma-se, em geral, interessado pela história desta Ciência e pode ir ao ponto de lamentar não ver no currículo do seu curso uma disciplina especificamente dedicada ao assunto.

Não seria contude viável sobrecarregar ainda mais um ensino que, quase por toda a parte, parece apostado em confundir o estatuto do estudante com o de aluno, enquadrando-o com solicitude (excessiva?), obrigando-o a uma aprendizagem variada (mas superficial?) e a um sistema de exames prolixo e fragmentado. Com optimismo e candura poderá ver-se aqui uma preocupação de infundir cultura - que é coisa que se não pode ensinar, mas que se aprende, se para isso forem oferecidos meios $e$, primeiro que tudo, vagar e disponibilidade para trabalho verdadeiramente individual e livre de tutela.

Nesta ordem de ideias, parece justificado restaurar a prática de oferecer, no contexto de uma disciplina, notas históricas - que o estudante lerá, estudará ou ignorará, a seu bel-prazer.

A história da preparação e usos do carbonato de sódio está de tal modo ligada a tanta coisa diversa, desde textos bíblicos à filosofia, da revolução industrial química às multinacionais, da arte do vidro e do vidro de arte ao progresso da química analítica, que o presente autor, impenitente estudante-livre, experimentou nela um gosto que desejaria partilhar. E essa a finalidade da breve resenha que a seguir se apresenta.

\section{Nomes, Usos e Métodos de Preparação}

O carbonato de sódio figura entre as 10 primeiras substâncias mais importantes na indústria química $\left[{ }^{1}\right]$.

É utilizado desde a antiguidade, nomeadamente em operações de limpeza (Jeremias 2, $22\left[^{2}\right]$ ), no embalsamamento, e na fabricação do vidro, manufacturado à escala industrial no Egipto a partir de 1370 a.C. [ $\left.{ }^{3}\right]$. Empregava-se nestas aplicaçð̃es o produto natural, constituinte dos depósitos que resultam da evaporação das águas fortemente mineralizadas de certos lagos ou mares interiores, como o Lago Natron, cerca de Mênfis, no Egipto. Ocorre também na cinza das plantas marinhas ou na das que crescem junto à orla marítima; as cinzas das plantas do interior são mais ricas em carbonato de potássio (Cf. [ [ $\left.{ }^{\mathbf{4}}\right]$ ).

Designado pelos egípcios por nater $\left[{ }^{2}\right]$, foi chamado nitrum em latim, e depois natron, vindo o uso a consagrar nitro para o nitrato de sódio $\left[{ }^{5}\right]$. Não seria estranha à dupla designação a presença simultânea dos dois sais, que consoante as suas proporçðes confeririam ao produto características diferentes. Razi (ca. 825-925) inclui o carbonato de sódio, sob o nome de qâly, na sua classificação das substâncias usadas em alquimia, na classe dos minerais, ordem dos sais; distingue-o do sal de cinzas de carvalho (carbonato de potássio), que coloca na mesma ordem $\left[{ }^{6}\right]$.

Em latim medieval passou a ser designado por soda, do nome árabe - swwâd - duma dicotiledónia que cresce à borda de água $\left[{ }^{7}\right]$. De soda derivam o português e o inglês, o castelhano sosa e o francês soude (soulde em 1527). Poderá supor-se que a introdução de novo nome, indicando outra origem do material, se relacione com o desenvolvimento (que igualmente se verificou na Idade Média [ $\left.{ }^{8}\right]$ da manufactura do sabão.

Em fins do século XVIII é designado por álcali mineral, sendo o carbonato de potássio o álcali vegetal (Cf. $\left[{ }^{9}\right]$ ). Este exemplo de tentativa para combinar, num mesmo termo descritivo, o carácter funcional e a origem duma espécie química revela talvez o domínio crescente da filosofia sobre as artes químicas. Em breve, porém, uma nova nomeclatura, expressamente adaptada à filosofia química de Lavoisier, virá dar definitiva preferência as descriptor baseado na conposição e no binómio género-espécie: o carbonato de sódio passará a chamar-se carbonato de soda $\left[{ }^{10}\right]$.

Até 1794 foi preparado por lexiviação de cinzas de plantas das regioes marítimas, sendo particularmente apreciadas as sodas "naturais» de Espanha, em especial as «barrillas» de Alicante e de Málaga, que continham até 20-25\% de carbonato de sódio [ $\left.{ }^{4}\right]$.

As dificuldades de abastecimento decorrentes da situação em que a França se encontrou após a revolução de 1789 , levaram a procurar processos de produzir soda artificialmente e a baixo custo. O Comité de Salut Publique oferecia um prémio a quem encontrasse um meio de fabricar soda a partir de sal marinho [ $\left.{ }^{8}\right]$, matéria-prima de que a França dispunha (salinas de Bayonne, por exemplo). Recorde-se que o carbonato de potássio (indispensável na refinação do salitre e portanto na fabricação da pólvora) podia ser, e era, produzido a partir de cinzas de plantas abundantes em França [ $\left.{ }^{11}\right]$, mas não convinha à fabricação do sabão por dar um produto excessivamente mole.

O químico Leblanc, deputado à Assembleia Legislativa, havia já registado em 19 de Setembro de 1791 a patente dum processo capaz de resolver o problema. Posteriormente, doa o processo à Nação e estabelece em Saint Denis (ao norte de Paris) uma fábrica com a capacidade de produção diária de 300 quilogramas de soda. Assegura assim, em plena crise, uma vasta expansão às

\footnotetext{
a Universidade de Évora, Departamento de Química, 7000 Évora. CECUL-INIC, Calçada Bento da Rocha Cabral, 14, 1200 Lisboa.
} 
indústrias de saboaria, vidraria, tinturaria e à recuperação do papel impresso [11].

O cloreto de sódio é primeiro transformado em sulfato, por reacção com ácido sulfúrico; o sulfato é depois reduzido a sulfureto, pelo carvão, em presença de calcário:

$$
\mathrm{Na}_{2} \mathrm{SO}_{4}+2 \mathrm{C}+\mathrm{CaCO}_{3}=\mathrm{CaS}+\mathrm{Na}_{2} \mathrm{CO}_{3}+2 \mathrm{CO}_{2} \text {. }
$$

A mistura era aquecida a cerca de $900^{\circ} \mathrm{C}$ num forno de revérbero e malaxada enquanto durasse a libertação de gases; a massa fundida era então retirada. Ambas as operações se realizavam à custa de trabalho braçal, muito penoso. Mais tarde passaram a utilizar-se fornos rotativos, exigindo maior investimento mas mais rentáveis. A separação do sulfureto de cálcio que, formado nestas condiçőes, é muito pouco solúvel, faz-se por lixiviação da mistura; ao concentrar a solução de carbonato de sódio, este separa-se por cristalização (Cf. [ $\left.{ }^{4}\right]$ ). O sulfureto de cálcio, desprovido de utilidade, era lançado em alto mar. Mais tarde passou-se a recuperar o enxôfre que continha por reacção com dióxido de carbono e vapor de água; o sulfureto de hidrogénio resultante era, por sua vez, oxidado a enxôfre pelo oxigénio do ar, em presença de óxido de ferro como catalisador (processo de Chancel-Claus):

$$
\begin{aligned}
\mathrm{CaS}+\mathrm{H}_{2} \mathrm{O}+\mathrm{CO}_{2} & =\mathrm{CaCO}_{3}+\mathrm{H}_{2} \mathrm{~S} \\
\mathrm{H}_{2} \mathrm{~S}+1 / 2 \mathrm{O}_{2} & =\mathrm{H}_{2} \mathrm{O}+\mathrm{S} .
\end{aligned}
$$

O carbonato de cálcio residual continha no entanto quantidades suficientemente altas de sulfureto para, por acção dos agentes atmosféricos, libertar sulfureto de hidrogénio e tornar o ambiente demasiado insalubre para os habitantes vizinhos dos locais onde se amontoava $\left[{ }^{8}\right]$

O processo Solvay é habitualmente tratado nos cursos de Química Inorgânica, o que se nos dispensa de descrevê-lo aqui. Conduz a um produto mais puro e é menos oneroso. Conhecido o seu fundamento já em 1838 (Dyar, Hennengen, Gray e Harisson), foi experimentado em França em 1855 por Rolland e Schloesing [ [ ${ }^{\mathbf{1}}$ ]. Em 1863 Solvay fê-lo entrar definitivamente na prática industrial, levando à desaparição progressiva do processo Leblanc. Este continuou no entanto a servir na produção do carbonato de potássio, visto que a solubilidade do respectivo hidrogenocarbonato é demasiado elevada para permitir aplicar o método de Solvay. Hoje em dia utiliza-se a acção do dióxido de carbono sobre o hidróxido de potássio, obtido por via electrolítica.

Em 1938 foram descobertos no estado de Wyoming, EUA, jazigos muito importantes de trona, sesquicarbonato de sódio monohidratado, mineral cuja existência na Hungria e na América era já conhecida em meados do século passado $\left[{ }^{12}\right]$. Por decomposição térmica a temperatura moderada dá o carbonato:

$\mathrm{Na}_{2} \mathrm{CO}_{3} \cdot \mathrm{NaHCO}_{3} \cdot \mathrm{H}_{2} \mathrm{O}=3 \quad \mathrm{Na}_{2} \mathrm{CO}_{3}+\mathrm{CO}_{2}+3 \mathrm{H}_{2} \mathrm{O}$.

A produção comercial começou em 1952. O carbonato bruto é dissolvido em água quente, os insolúveis separados por filtração e os vestígios de matéria orgânica eliminados por adsorpção sobre carvão. Ao concentrar a solução, formam-se cristais de carbonato de sódio monohidratado, fáceis de separar.
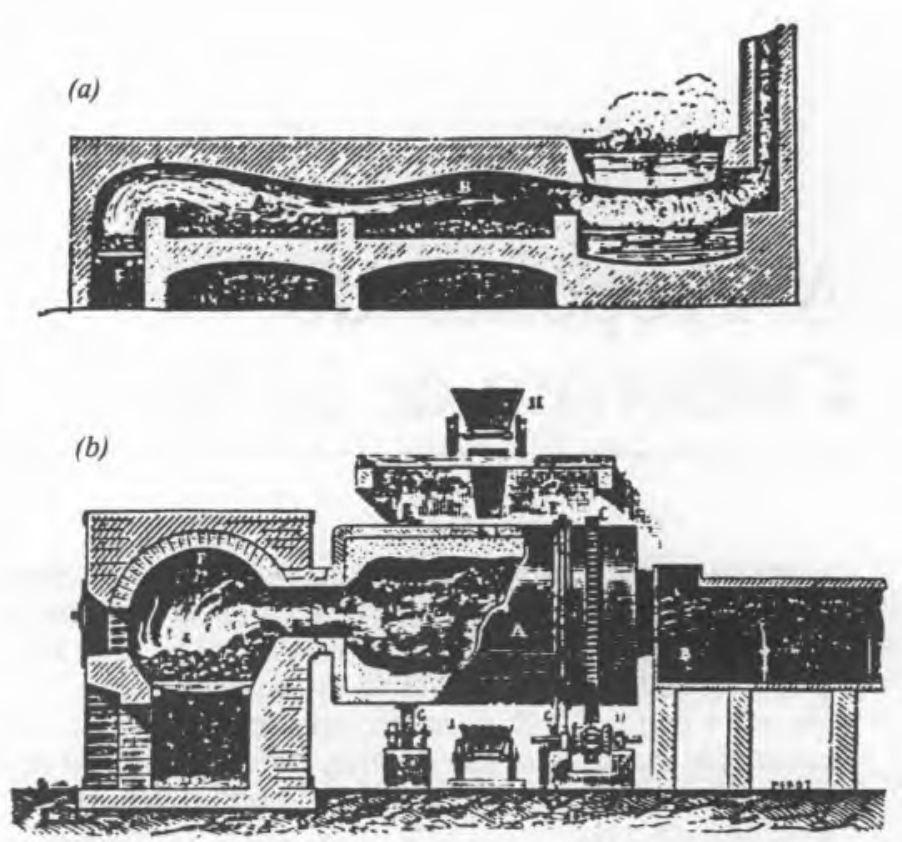

(c)

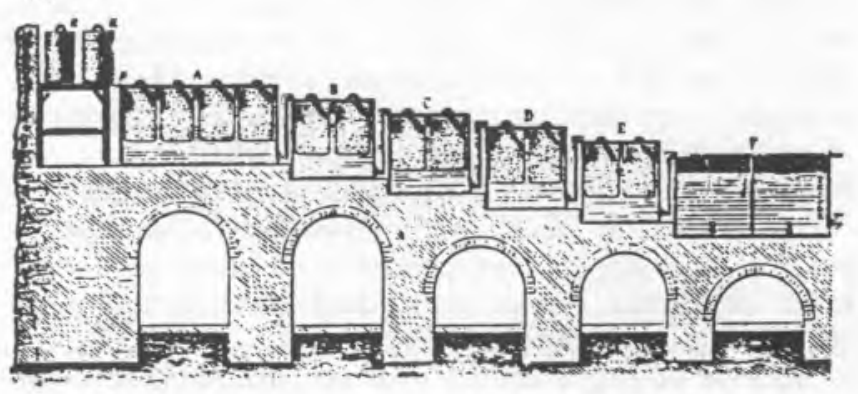

Fabricação da soda pelo processo Leblanc

(a), forno de revérbero e caldeira para a concentraçâo das lixtvias de soda; (b), forno rotativo para a fabricação da soda; (c), instalação para a lixiviaçâo metódica da soda bruta.

[Reproduzido de Troost, ob. cit., pp. 500-1I]

Nos Estados Unidos produziam-se em 19777 milhões de toneladas de carbonato de sódio por ano, dos quais 5 milhőes obtidos a partir de trona. Das noves instalaçð̃es Solvay existentes fecharam, até então, seis. As reservas de trona, só no Wyoming, são avaliadas em 60000 milhōes de toneladas $\left.{ }^{[12}\right]$.

\section{O Carbonato de Sbdio \\ na Origem da Revolução Química Industrial}

O processo Leblanc trouxe consigo a necessidade de se produzir grandes quantidades de ácido sulfúrico. A disponibilidade de ácido sulfúrico abundante e barato veio mais tarde a promover a indústria da química orgânica, dos corantes em particular, e a dos adubos. Por outro lado, o ácido clorídrico, subproduto do processo Leblanc, encontrou aplicação na fabricação da cal clorada ou «cloreto de cal», empregado como desinfectante e como descorante. Substituivel com vantagem pela solução de hipoclorito de sódio, era ainda muito usado há trinta anos.

A «soda Leblanc» esteve assim, sem dúvida alguma, na base do desenvolvimento da indústria química no princípio do século XIX, tanto em França, donde partiu, 
como em Inglaterra. O processo não é, todavia, citado nos Quadros Sinópticos de Química de Fourcroy de $1800\left[{ }^{10}\right]$, onde se refere o método tradicional. A supressão do bloqueio a que a França estivera sujeita explicará o retorno, temporário, ao antigo processo, que exigia menores investimentos $\left[{ }^{8}\right]$. O processo Leblanc não deixou contudo de suscitar o interesse de novos industriais. Leblanc suicidou-se, em 1806, num hospital para pobres, em Paris [ $\left.{ }^{8}\right]$.

Em 1805, a Companhia Saint-Gobain utilizava na manufactura dos seus vidros "soda Leblanc», proveniente da fábrica de Darcet em Paris. No ano seguinte a Companhia instalava uma fábrica própria em Charlesfontaine que, doze anos depois, produzia anualmente cerca de 500 toneladas de soda bruta, cobrindo quase as necessidades do fabrico do vidro $\left[{ }^{13}\right]$. Seguindo um parecer de Gay-Lussac, membro do Conselho de Administração com o cargo de Censor, a fábrica de soda foi transferida em 1822 para Chauny, próximo da manufactura de vidro. As instalações compreendiam, naturalmente, uma fábrica de ácido sulfúrico.

Foi nesta fábrica que Gay-Lussac procurou baixar o custo da produção (e diminuir a contaminação da atmosfera), absorvendo os óxidos de azoto residuais das câmaras de chumbo por lavagem com ácido sulfúrico. O método que utilizava para recuperar o óxido de azoto - decomposição do sulfato de nitrosilo pelo vapor de água, a quente - tinha porém o inconveniente de diluir o ácido. Assim, embora permitisse poupar $75 \%$ do salitre dispendido, o processo de recuperação só veio a ter aceitação geral quando o inglês Glover pôs em prática a decomposição do sulfato de nitrosilo pelo próprio ácido das câmaras, a uma temperatura suficientemente elevada. As torres de Gay-Lussac e de Glover, passaram a constituir, a partir de 1870 , o complemento indispensável das câmaras de chumbo $\left[{ }^{13}\right]$, e assim continuou a ser até que $\mathrm{o}$ método de contacto veio substituir o das câmaras, já em meados do nosso século.

Em Portugal a primeira instalação de contacto foi estabelecida em 1949 na fábrica do Barreiro da Companhia União Fabril: as câmaras de chumbo foram sendo gradualmente substituídas no decurso dos anos 50 e a última encerrada em 1960. Por seu lado, a SAPEC manteve em laboração até ao ano passado, em Setúbal, uma instalação de câmaras de chumbo [ $\left.{ }^{14}\right]$. Mereceria ser conservada, como parte do nosso património de Arqueologia Industrial.

Referimos já que a fabricação da "soda Leblanc» originava como subproduto grandes quantidades de ácido clorídrico. Este viria a encontrar uma aplicação muito importante na produção do cloro.

Berthollet, investido em 1784 no cargo de Comissário para a direcção das Tapeçarias, superintendia na Manufactura Real dos Gobelins as operaçőes de tinturaria e do branqueamento prévio dos fíos e dos tecidos [ $\left.{ }^{11,15}\right]$. O processo habitual consistia na sua exposição à luz solar, ao ar e à chuva ou orvalho, alternando com lavagens com lixívias alcalinas; demorava vários meses e exigia como estendais prados de grandes dimensões. Em 1785, Berthollet introduz o uso do cloro, em solução aquosa diluida, para a oxidação das matérias corantes indesejáveis, em substituição dos agentes atmosféricos: apenas alguns dias bastavam para obter têxteis perfeitamente brancos, e as fibras sofriam menos com o novo tratamento $\left[{ }^{15,16}\right]$.
A água de cloro contém apenas 2 a 3 vezes o seu volume de cloro. Absorvendo este gás pela cal húmida, obtém-se um produto que consiste essencialmente numa mistura de hipoclorito com cloreto básico de cálcio e pode despender até 200 vezes o seu volume de cloro. Contornava-se assim a dificuldade em transportar um gás muito corrosivo ou a sua solução, instável. O «cloreto de cal» passou a ser empregado como descorante, não só na indústria têxtil, como na do papel, e como desifectante nas oficinas, nas prisões, nos hospitais, nos esgotos $\left[{ }^{15}\right]$.

Recordemos que, já em 1818, a produção anual de soda bruta de Saint-Gobain correspondia, em números redondos, a 300 toneladas de carbonato de sódio que eram absorvidas pela fabricação do vidro. Para tal era necessário o mínimo de 280 toneladas de ácido sulfúrico que se convertiam em 200 de ácido clorídrico. Este permitiria obter até $70000 \mathrm{~m}^{3}$ de cloro com o que se poderia fabricar 700 toneladas de cloreto de cal com um título típico de $100^{\circ}$ clorimétricos $(1001 \mathrm{de}$ cloro $/ \mathrm{kg})$.

Em 1835 Saint-Goban vendia 1,7 milhões de francos de produtos químicos e 2,4 de vidro; contavam-se entre esses produtos, além do ácido sulfúrico, "cloreto de cal», ácido clorídrico, carbonato de sódio, sulfato de sódio e cloreto estanoso $\left[{ }^{13}\right]$. Da sua produção de soda (que representa então $15 \%$ da produção francesa), $75 \%$ era destinada a uso próprio; em 1847 a proporção passa a $15 \%$, «A actividade química torna-se verdadeiramente $o$ arcobutante da dos vidros, desempenhando o papel de elemento securisante de diversificação" [ [ $\left.{ }^{17}\right]$. Após a sua fusão com Saint-Quirin (1858) e depois com Kuhlmann e com Perret-Olivier, Saint-Gobain representa mais de $30 \%$ da química de base francesa em 1872 . A antiga "Manufacture Royale des Glaces de Miroirs", fundada sob Luis XIV e Colbert tornou-se pois, pela via da "soda Leblanc", a grande empresa multinacional que é hoje. Nacionalizada, em 1982, reprivatizada em 1986, foi durante muito tempo a única empresa francesa a ter a honra de ser habitualmente citada nos manuais escolares. A sua história foi recentemente contada num belo livro (embora dum ponto de vista mais empresarial que tecnologico) $\left[{ }^{17}\right]$.

\section{Extensão e Aperfeiçoamento dos Métodos Volumétricos de Análise}

A análise volumétrica pode ir buscar as suas origens ao século XVI. Foram no entanto os problemas suscitados pelas artes químicas, já en fins do século XVIII, que levaram a desenvolver métodos volumétricos, expeditos e rigorosos $\left[{ }^{13}\right]$.

A avaliação da qualidade duma "barrilla» ou duma soda, isto é, do seu teor em carbonato de sódio, podia fazer-se adicionando ácido sulfúrico, contido numa proveta graduada, sobre a solução de soda contida num copo, até que um gota desta avermelhasse o papel azul de tornesol. O método, estabelecido por Welter, discípulo de Berthollet, é descrito por este último em 1804 [18].

De maneira semelhante, Descroizilles, farmacêutico em Ruão, serve-se duma proveta graduada, a que chama «berthollimètre», para avaliar o teor duma água de cloro (lixivia de Berthollet) pelo volume necessário para descorar uma solução de indigo $\left.{ }^{16}\right]$. Em 1794, 
Descroizilles utilizava o mesmo método para avaliar a qualidade dum "cloreto de cal» $\left[{ }^{19}\right]$.

Foi porém Gay-Lussac quem, a partir de 1820, introduziu os melhoramentos decisivos que tornaram a análise volumétrica mais expedita ainda, e lhe permitiram satisfazer os critérios de precisão e de exactidão que permanecem os nossos. Neste sentido, pode considerar-se Gay-Lussac como o fundador da volumetria.

(a)
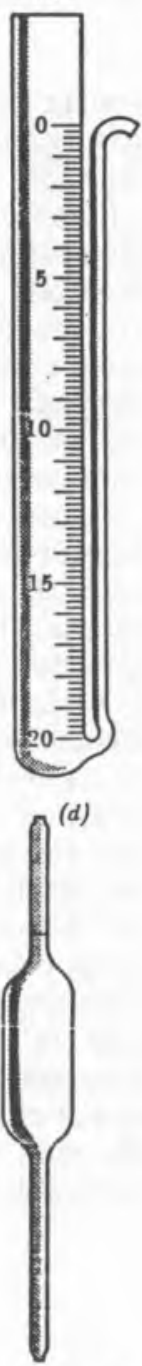

Material volumétrico criado ou melhorado por Gay-Lussac

(a), bureta; (b), pipeta de 1824; (d), pipeta de 1832. [Reproduzido de Crosland, ob. cit., p. 212]

O seu ponto de partida terá sido o problema da avaliação da qualidade das sodas sobre o qual publica um estudo, em colaboração com Welter $\left[{ }^{20}\right]$.

Em primeiro lugar, inventa um bureta mais cómoda e precisa que as provetas de Descroizilles e de Welter: o volume de titulante pode ser determinado com uma precisão de 2 a 4 por mil. $O$ indicador continua a ser o tornesol, mas interno, agora. No que respeita à exactidão, virá a propor $\left[{ }^{21}\right]$, como padrão para o doseamento da soda, o ácido sulfúrico de concentração máxima, de densidade 1,8427 a $15^{\circ} \mathrm{C}$, diluido de $100 \mathrm{~g}$ a 11 . O padrão é pois mais exactamente definido que o de Descroizilles, que se servia do ácido comercial, de $66^{\circ}$ Beaumé, sem indicação da temperatura.

Enfim, mediante uma escolha adequada das tomas, Gay-Lussac consegue obter directamente, pela leitura da bureta, a percentagem de soda na amostra: $5,40 \mathrm{~g}$ de carbonato de sódio puro requerem para neutralização $50 \mathrm{ml}$ do ácido padrão. $\mathrm{Na}$ bureta, $50 \mathrm{ml}$ estão divididos em 100 divisð̃es. Assim, se com uma toma de exactamente $5,40 \mathrm{~g}$ duma soda do comércio se gastam para a neutralização 83 divisð̃es, a soda contém $83 \%$ de carbonato de sódio.

Também no doseamento do "cloro activo" do "cloreto de cal» Gay-Lussac trouxe uma contribuição importante. De início não pretendia conseguir uma exactidão melhor que $2 \%$, utilisando como titulante o indigo; alguns anos depois, em 1828, atingia uma exactidão de $1 \%$, «bastante para quaisquer fins práticos» $\left[{ }^{21}\right]$. Todavia, e no mesmo espírito que acima vimos, procura um padrão mais estável e exacto que o indigo: é o ácido arsenioso; o indigo passa a ser usado como indicador apenas (1835) [ $\left.{ }^{22}\right]$. Em qualquer dos casos, a simples leitura da bureta permitia obter o título da cal clorada em litros de cloro por quilograma. (Uma tabela ad hoc, permitia converter o volume a PTN).

Mas o mais famoso e exacto doseamento volumétrico estabelecido por Gay-Lussac na sequência das pesquisas analíticas iniciadas com o carbonato de sódio, foi o da determinação do título das moedas de prata.

A lei de 28 de Março de 1803 havia definido o franco como uma moeda de $5 \mathrm{~g}$ duma liga de prata e cobre, contendo $90 \%$ de prata, com uma tolerância de $25 \mathrm{mg}$ no peso e de 3 milésimos de título [Cf. 23]. A verificação do título fazia-se por cupelação, processo que dá resultados 4 a 5 milésimos mais baixos que o teor real. Para manter a confiança na moeda, esta era portanto fabricada com um título de 904 milésimos, isto é com valor superior ao valor nominal e consequente prejuízo para o Estado. A questão, debatida entre as principais Casas da Moeda da Europa, nomeadamente o Hôtel de la Monnaie de Paris e a Royal Mint de Londres [ ${ }^{\mathbf{2 4}}$ ], veio a ser resolvida por uma volumetria de precipitação da prata com cloreto de sódio. Gay-Lussac garantia, logo de início, uma exactidão de 2 por mil ou melhor. Com o emprego de duas soluçð̄es - a "normal», correspondendo $100 \mathrm{ml}$ a $1 \mathrm{~g}$ de prata, e a "décima», dez vezes mais diluída - o método permite atingir uma exactidão de 0.5 milésimos [24,25].

Por decreto de 6 de Junho de 1830 , era deixado ao ensaiador, como tradicionalmente, a livre escolha do método de ensaio, nos ensaios ordinários; mas para contraprova apenas o método de Gay-Lussac teria, doravante, valor legal $\left[{ }^{26}\right]$. E ainda actualmente o método de referência nas Casas da Moeda, em particular na de Paris [ $\left.{ }^{27}\right]$.

Burette, pipette, titre, tirer, titrage - palavras que passaram da França para a Inglaterra, para a Espanha, para Portugal. E que testemunham como o interesse e envolvimento nos problemas técnicos constituem um (um!) dos motores do desenvolvimento científico. Quisemos também apontar como o engenho e o espírito de rigor constituem outro, fazendo tudo parte duma mesma dinâmica em que, do iluminismo ao romantismo, se reuniram, de maneira particularmente feliz, as artes e a filosofia química.

Voltemos porém ao carbonato de sódio, nosso ponto de partida. E terminemos recordando Leblanc: o inventor generoso que fez dom da sua patente «à Nação», e da qual outros souberam tirar melhores proveitos. 


\section{Referências}

[1] M. Hudson, "Why Should we teach Descriptive Chemistry». J. Chem. Ed. 57, 700 (1980).

[2] La Sainte Bible, trad. Ecole Biblique de Jérusalem. Les Editions du Cerf, Paris, 1961, p. 1058.

[3] J.R. Partington, «Historia de la Química». Trad. C.E. Prélat, Espasa-Calpe, Madrid, 1945, p. 28.

[4] L. Troost, "Traité Elèmentaire de Chimie». 9e. ed. Masson, Paris, 1887 , pp. 472 e ss, e 499 e ss.

[5] E.H. Riesenfeld, "Tratado de Química Inorgânica». Trad. J.M. Sauras, Marin, Buenos Aires, 1949, p. 413.

[6] E.J. Holmyard, «Alchemy». Penguin Books, 1957, pp. 88-9.

[7] P. Robert, "Le Petit Robert». Dictionnaire Alphabètique et Analogique de la Langue Française». Société du Nouveau Litré, Paris, 1970 , p. 1675.

[8] E.H. Riesenfeld, ob. cit., pp. 437-439.

[9] «Encyclopédie Méthodique, Médicine». Panckoucke, Paris, 1792, t. V, pp. 622 e 629.

[10] A.F. Fourcroy, "Méthode de Nomenclature Chimique proposée par MM. de Morveau, Lavoisier, Bertholet et de Fourcroy». Cuchet, Paris, 1787.

- Id., «Elèments d'Histoire Naturelle et de Chimie». 4e. éd. Cuchet, Paris, 1791, t. 2, p. 6.

- Id., "Taboas Synopticas de Química». Trad. G.J. de Seixas, Regia Officina Typographica, Lisboa, 1802, p. 86.

[11] D. Gedj, «La Révolution des Savants» V. 48 Col. Découvertes Gallimard Sciences. Gallimard, Paris, 1988, pp. 14-15 e 105-106.

[12] "The Modern Inorganic Chemicals Industry». Ed. R. Thomp-

son. The Royal Society of Chemistry, London, 1977, p. 132.

[13] M. Crosland, "Gay-Lussac Scientist and Bourgeois». Cambridge University Press, 1978, pp. 195 e ss.

[14] Comunicação Pessoal do Engenheiro Leal da Silva, Quimigal. A conservação das câmaras de chumbo representa infelizmente um encargo não produtivo muito elevado: ocupação de espaço, empate de grande quantidade de chumbo, manutenção da estrutura geralmente em madeira.
A Sigla SAPEC corresponde a SAPEC - Produits et Engrais Chimiques du Portugal SA.

[15] L. Troost, ob. cit., pp. 246 e 541 e ss.

- M. Michaud, Ed., «Biographie Universalle Ancienne et Moderne». Thoisnier Desclaces, Paris, 1843, T. 4, p. 144.

[16] C.L. Berthollet, «Description du blanchissement des toiles et des fils avec l'acide muriatique oxygéné, et de quelques propriétes de cette liqueur relativement aux arts", Annales de chimie 2 (1789) 151; ibid. 6 (1790) 204.

[17] M. Hamon. "Du Soleil à la Terre, Une Histoire de Saint-Gobain", J.C. Latès, 1988, pp. 60-61.

[18] C.L. Berthollet, «Eléments de l'Art de la Teinture», 2e. ed., Paris, 1804 , v. 1 , p. 235.

[19] L. Troost, ob. cit., pp. 543 e ss.

[20] J.L. Gay-Lussac, "Observations sur l'essai des souds et des sels de soud de commerce», Annales de chimie et de physique, 13 (1820) 212-21.

[21] Id., "Instruction sur l'essai du chlorure de chaux», ibid. 26 (1824) $162-76$.

- Id., ibid. 39 (1828) 349.

[22] Id., "Nouvelle instruction sur la chlorométrie», obid., 60 (1835) 225-61.

- Cf. tb. Troost, ref. 19.

[23] J.-M. Darnis, «La Monnaie de Paris. Sa création et son histoire du Consulat et de l'Empire à la Restauration (1795-1826)". Centre d'Etudes Napoléoniennes, Levallois, 1988, p. 134.

[24] J.L. Gay-Lussac, «Rapport sur le mode d'essai des matières d'argent", Paris, le 1er. Mars 1830. In "Report from the Select Commitee on the Royal Mint \&...", The House of the Commons, 30 June 1837. (B) Apendix 31, p. 120.

[25] J.L. Gay-Lussac, «Instruction sur l'essai des matières d'argent par la voie humiden. Imprimerie Royale, Paris, 1832, 4 to., 88 pp. + figs.

- Cf. tb. L. Troost, ob. cit., p. 666.

[26] M. Crosland, ob. cit., p. 190.

[27] J.-M. Darnis, ob. cit., p. 140.

\section{SPQ - QUOTAS}

Sócio Efectivo

\section{BOLETIM}
Assinatura (4 números)
$1500 \$ 00$ (no país)
US\$35 (no estrangeiro)
Número avulso. 


\section{CURSO DE MESTRADO EM QUÍMICA ORGÂNICA TECNOLÓGICA}

Início: O início do curso está previsto para 6 de Novembro de 1989.

Duração normal do curso: A parte escolar do curso é constituída por 3 períodos, com duração aproximada de 3 meses cada um, seguida de um projecto de investigação com a duração de 1 ano, que conduzirá à elaboração de uma dissertação.

Local de ensino: A maior parte do ensino será ministrado no Centro de Formação Técnica do L.N.E.T.I., ao abrigo de um convénio entre a Universidade Nova de Lisboa e o L.N.E.T.I.

Plano de estudos:

Disciplinas integrantes

I - QUÍMICA ORGÂNICA: ESTRUTURA E REACTIVIDADE

1 - Fontes de Informação em Química

2 - Química Orgânica Funcional

3 - Estereoquímica

4 - Mecanismos em Química Orgânica

5 - Química Orgânica Física

UNIVERSIDADE NOVA DE LISBOA

Faculdade de Ciências e Tecnologia

Serviços Académicos

Quinta da Torre - 2825 MONTE DA CAPARICA

Telefone: 2954464

LABORATÓRIO NACIONAL DE ENGENHARIA E TECNOLOGIA INDUSTRIAL Centro de Formação Técnica

Azinhaga dos Lameiros à Estrada do Paço do Lumiar - 1699 LISBOA CODEX

Telefone: 7582712 